\title{
Mild iron overload in patients carrying the HFE S65C gene mutation: a retrospective study in patients with suspected iron overload and healthy controls
}

\author{
P Holmström, J Marmur, G Eggertsen, M Gåfvels, P Stål
}

See end of article for authors' affiliations

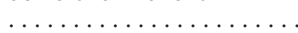

Correspondence to: Dr P Stål, Unit of

Gastroenterology and Hepatology, Department of Internal Medicine,

Karolinska Institutet,

Danderyds Hospital, S-182

88 Stockholm, Sweden

Per.Stal@med.ds.sll.se

Accepted for publication 5 March 2002

\begin{abstract}
Background and aims: The role of the HFE S65C mutation in the development of hepatic iron overload is unknown. The aim of the present study was: (A) to determine the HFE S65C frequency in a Northern European population; and $(B)$ to evaluate whether the presence of the HFE S65C mutation would result in a significant hepatic iron overload.

Patients and methods: Biochemical iron parameters and HFE mutation analysis (for the C282Y, H63D, and S65C mutations) were analysed in 250 healthy control subjects and collected retrospectively in 296 patients with suspected iron overload (elevated serum ferritin and/or transferrin saturation). The frequency of patients having at least mild iron overload, and mean serum ferritin and transferrin saturation values were calculated for each HFE genotype. For patients carrying the S65C mutation, clinical data, liver biopsy results, and amount of blood removed at phlebotomy were determined.

Results: The HFE S65C mutation was found in 14 patients and eight controls. In controls, the S65C allele frequency was $1.6 \%$. The S65C allele frequency was enriched in non-C282Y non-H63D chromosomes from patients $(4.9 \%)$ compared with controls $(1.9 \%)(p<0.05)$. Serum ferritin was significantly increased in controls carrying the S65C mutation compared with those without HFE mutations. Fifty per cent of controls and relatives having the S65C mutation had elevated serum ferritin levels or transferrin saturation. The number of iron overloaded patients was significantly higher among those having HFE S65C compared with those without any HFE mutation. Half of patients carrying the S65C mutation $(7 / 14)$ had evidence of mild or moderate hepatic iron overload but no signs of extensive fibrosis in liver biopsies. Screening of relatives revealed one S65C homozygote who had no signs of iron overload. Compound heterozygosity with S65C and C282Y or H63D did not significantly increase the risk of iron overload compared with S65C heterozygosity alone.

Conclusions: The HFE S65C mutation may lead to mild to moderate hepatic iron overload but neither clinically manifest haemochromatosis nor iron associated extensive liver fibrosis was encountered in any of the patients carrying this mutation.
\end{abstract}

$\mathrm{H}$ ereditary haemochromatosis (HH) is a common autosomal recessive disorder of iron metabolism leading to enhanced iron absorption and progressive iron deposition in parenchymal organs, most notably in the liver. ${ }^{1}$ With time, excess iron may cause damage to parenchymal organs, with an increased risk of developing diabetes mellitus, arthropathy, liver cirrhosis, and hepatocellular carcinoma. ${ }^{23} \mathrm{~A}$ candidate gene for HH called HFE (originally named HLA-H) was identified in $1996 .{ }^{4}$ It was found to be located near the major histocompatibility complex (MHC) locus on chromosome $6 \mathrm{p}$. Eighty three per cent of $\mathrm{HH}$ patients were found to be homozygous for a point mutation resulting in a substitution of cysteine for tyrosine at amino acid 282 (C282Y). Also, a second mutation (H63D) was identified but was not associated with iron overload to the same extent as $\mathrm{C} 282 \mathrm{Y}^{4}$

The HFE gene product is a membrane bound MHC class I-like molecule expressed in a low amount in a wide spectrum of tissues. Highest expression is found in the liver and small intestine - that is, organs involved in iron metabolism. ${ }^{4}$ Proper cell surface expression of the HFE protein requires interaction with $\beta_{2}$ microglobulin. ${ }^{5} \beta_{2}$ microglobulin deficient mice have increased intestinal iron absorption and develop progressive iron overload similar to that seen in $\mathrm{HH}$ patients. ${ }^{6}$

The HFE protein complexes with the transferrin receptor (TfR) and decreases the binding affinity of TfR to transferrin (Tf). ${ }^{89}$ As a consequence, uptake of Tf bound iron by cells and accumulation of intracellular iron are reduced in the presence of HFE. The C282Y mutation disrupts the non-covalent interaction with $\beta_{2}$ microglobulin. ${ }^{5}$ Consequently, the C282Y HFE mutant protein is not expressed on the cell surface, ${ }^{10}$ leaving TfR free to bind Tf. Loss of HFE function promotes intestinal iron uptake. Unlike the $\mathrm{C} 282 \mathrm{Y}$ mutation, the H63D mutation does not affect binding to $\beta 2$ microglobulin. The H63D HFE mutant protein is expressed at the cell surface and complexes with TfR but it does not decrease TfR affinity for Tf to the same extent as wild-type HFE. ${ }^{5} 10$

The prevalence of homozygosity for $\mathrm{C} 282 \mathrm{Y}$ is approximately $0.5 \%$, and the level of healthy carriers of the recessive allele is $9.5-14.1 \%$ in certain populations of Northern European ancestry, ${ }^{11-13}$ making $\mathrm{HH}$ one of the most common inherited diseases in these populations. In Scandinavia, the allele frequencies of the $\mathrm{C} 282 \mathrm{Y}$ mutation are within the range found in other Northern European populations (Sweden 0.0540.077 and Finland 0.046). ${ }^{14}$ Gene frequencies are lower in other ethnic groups (Hispanic, Black, Asian, and Swedish Saamis). ${ }^{11}{ }^{15}$

Abbreviations: $\mathrm{HH}$, hereditary haemochromatosis; $\mathrm{MHC}$, major histocompatibility complex; Tf, transferrin; TfR, transferrin receptor; HIS, hepatocyte iron score; SIS, sinusoidal iron score; RFLP, restriction fragment length polymorphism. 
Homozygosity for the $\mathrm{C} 282 \mathrm{Y}$ mutation has been recorded in $80-92 \%$ of $\mathrm{HH}$ patients of Northern European origin $^{5} 121416$ whereas a lower frequency of the C282Y mutation was found in $\mathrm{HH}$ patients of Mediterranean origin. ${ }^{17-20}$ Only $5-7 \%$ of $\mathrm{HH}$ patients are compound heterozygotes for C282Y/H63D whereas heterozygosity for $\mathrm{C} 282 \mathrm{Y}$ alone, or homozygosity for $\mathrm{H} 63 \mathrm{D}$, is rarely encountered in $\mathrm{HH} .{ }^{17}$ Compound heterozygotes generally show less severe iron overload compared with C282Y homozygotes. In $\mathrm{HH}$ patients carrying neither C282Y homozygosity nor C282Y/H63D compound heterozygosity, other mutations are possibly of importance for increased iron absorption.

Such rare HFE mutations (G93R and I105T) have been reported in individual families. ${ }^{21}$ Also, patients carrying a homozygous nonsense mutation (Y250X) in the TfR2 gene on chromosome 7q22 develop HH not linked to HFE. ${ }^{22}$ The clinical importance of these recently reported mutations remains unclear.

A third mutation in the HFE gene, $565 \mathrm{C}$, was found to be enriched on chromosomes from French $\mathrm{HH}$ patients compared with healthy controls. ${ }^{12}$ However, its clinical importance remains controversial as the $\mathrm{S} 65 \mathrm{C}$ variant was found not to be associated with increased Tf saturation in healthy Canadian blood donors. ${ }^{23}$ The allelic frequency of S65C was $0.6-1.95 \%$ in Caucasian populations. ${ }^{11}{ }^{12} 21$ In these studies, the phenotypic expression of the S65C mutation was not evaluated. To further explore the significance of the S65C variant for any possible clinical manifestation of iron overload, we performed a study on the C282Y, H63D, and S65C variants of the HFE gene in healthy controls and retrospectively in patients with a clinical suspicion of iron overload. Patients carrying the S65C mutations were followed up for biochemical iron parameters, degree of hepatic iron overload (liver biopsy), and amount of blood removed at phlebotomy.

\section{PATIENTS AND METHODS \\ Healthy controls}

A total of 250 healthy control subjects participated in the study. None had a history of liver disease or had received multiple blood transfusions. They were recruited from hospital staff, students, and their relatives. Written consent was given.

Blood samples were collected from each subject for analysis of serum ferritin, Tf saturation, and haemoglobin count. HFE mutation analysis was performed on all subjects.

\section{Patients with clinical indications of iron overload}

The study group of patients was selected from those genotyped for HFE mutations at the Division of Clinical Chemistry, Huddinge University Hospital from l October 1997 to 19 September 2000. All patients having: (1) serum ferritin $>300 \mu \mathrm{g} / \mathrm{l}$ (males) or $>200 \mu \mathrm{g} / \mathrm{l}$ (females); or (2) Tf saturation $>50 \%$ (males) or $>45 \%$ (females) were included, except for those patients found by family screening or those related to another subject in the study, who were excluded. Another 17 patients were excluded who had hyperferritinaemia due to acute hepatitis, acute liver failure, hepatocellular carcinoma, thyreotoxicosis, acute leukaemia, or myelodysplastic syndrome. In total, 296 patients were included in the study. Apart from HFE mutation analysis, values for serum ferritin and/or Tf saturation, and haemoglobin count were collected retrospectively from patient files from the time of diagnosis (before any phlebotomy treatment had been initiated). In 78 cases, the exact serum ferritin value at the time of diagnosis could not be found, and in 90 patients data on Tf saturation were missing.

Clinical data concerning iron staining of liver biopsies (if performed), and whether or not patients had undergone phlebotomy were extracted from patient files for 231 of 296 patients. Patients with hepatic iron staining of grade 1 or more (see below) or who had been treated with phlebotomies were classified as having iron overload.

\section{Patients carrying the HFE S65C mutation}

In patients carrying the HFE S65C mutation, clinical data were collected from patient files. Alcohol consumption, hepatitis B and C serology, and activity levels of serum alanine aminotransferases were evaluated. Liver biopsy had been performed in seven patients. Iron deposition in hepatocytes was described using the "hepatocyte iron score" (HIS) and scored as follows: grade $0=$ no stainable iron; grade $\mathrm{l}=$ faint bluish colour with small non-coalescent iron granules in zone 1 hepatocytes ${ }^{24}$; grade $2=$ iron granules in the majority of zone 1 hepatocytes, occasionally coalescent; grade $3=$ marked iron deposition with coalescent granules; and grade $4=$ massive iron deposition in hepatocytes of the entire lobule. Sinusoidal cell iron deposits were described by the "sinusoidal iron score" (SIS) and scored as present $=1$ or $a b s e n t=0$. Fibrosis was staged as follows: stage $0=$ absent; stage $1=$ non-extensive portal fibrosis; stage 2 =xtensive portal fibrosis; stage 3 =bridging fibrosis; and stage $4=$ cirrhosis. In patients diagnosed as having iron overload and undergoing phlebotomies, redrawn quantities of blood were noted.

\section{Mutation analysis}

Human genomic DNA was extracted from peripheral blood leucocytes using Qiagen Blood and Cell Culture DNA Midi Kit (Qiagen GmbH, Hilden, Germany).

In the control material, identification of mutations in the HFE gene causing the amino acid exchanges C282Y, H63D, and $\mathrm{S} 65 \mathrm{C}$ was carried out by restriction fragment length polymorphism (RFLP), essentially as described previously. ${ }^{32} 16$ Electrophoresis was performed on precast polyacrylamide gels (GeneGel Excel 12.5/24 Kit) using the GenePhor DNA Separation System (Pharmacia Biotech AB, Uppsala, Sweden). Bands were visualised by silver staining (PlusOne DNA Silver Staining Kit; Pharmacia Biotech AB, Uppsala, Sweden). All substitutions detected by RFLP were confirmed, either by repeating RFLP testing $(\mathrm{C} 282 \mathrm{Y})$ or by automatic sequence analysis (H63D, S65C).

In the patient material automatic DNA sequence determination was used, corresponding to the first half of exon 2 and the whole of exon 4, using the ABI Prism Big Dye Primer Cycle Sequencing Kit on an ABI Prism 377 DNA Sequencer (PE Applied Biosystems, Norwalk, Connecticut, USA).

Screening for the Y250X mutation in the TfR2 gene was performed in 44 patients by restriction enzyme digestion, according to Camaschella and colleagues. ${ }^{22}$

\section{Biochemical measurements}

Serum levels of ferritin, Tf, and iron were determined by automated turbidimetry/nephelometry or spectrophotometry using dye binding reagents (Boehringer Mannheim or Dako) on a Hitachi 917 analyser. Tf saturation was calculated according to the formula $4(\mathrm{p}$-iron/p-Tf). Total haemoglobin value was determined on whole blood samples.

\section{Statistical analysis}

Gene frequencies were compared between patients and controls using Fisher's exact test. The number of patients and controls with iron overload in each genotype were compared using Fisher's exact test. Only unrelated subjects were compared.

Serum biochemical parameters were compared using analysis of variance (ANOVA) (Fisher's PLSD). A p value less than 0.05 was considered statistically significant.

\section{Ethics committee}

The study was approved by the human ethics committee at Huddinge University Hospital

\section{RESULTS}

\section{Age and sex of controls and patients}

Mean age of the controls was 47.7 (SD 17.9) years and for patients 54.5 (SD 14.8) years $(\mathrm{p}<0.001$, Fisher's exact test). 
Table 1 Frequencies of different HFE genotypes in control subjects and patients with increased ferritin and/or transferrin saturation (values in parentheses are percentages)

\begin{tabular}{lllcc}
\hline C282Y & H63D & S65C & $\begin{array}{c}\text { Patients } \\
(\mathrm{n}=296)\end{array}$ & $\begin{array}{c}\text { Controls } \\
(\mathrm{n}=250)\end{array}$ \\
\hline$+/+$ & $-/-$ & $-/-$ & $84(28.4)^{* * *}$ & $1(0.4)$ \\
$-/-$ & $+/+$ & $-/-$ & $7(2.4)$ & $7(2.8)$ \\
$+/-$ & $+/-$ & $-/-$ & $21(7.1)^{* * *}$ & $2(0.8)$ \\
$+/-$ & $-/-$ & $+/-$ & $2(0.7)$ & $1(0.4)$ \\
$-/-$ & $+/-$ & $+/-$ & $3(1.0)$ & $1(0.4)$ \\
$+/-$ & $-/-$ & $-/-$ & $28(9.5)$ & $26(10.4)$ \\
$-/-$ & $+/-$ & $-/-$ & $49(16.6)$ & $40(16.0)$ \\
$-/-$ & $-/-$ & $+/-$ & $9(3.0)$ & $6(2.4)$ \\
$-/-$ & $-/-$ & $-/-$ & $93(31.4)^{* * *}$ & $166(66.0)$ \\
\hline
\end{tabular}

${ }^{* * *} p<0.001$ compared with controls (Fisher's exact test).

Sixty four per cent of controls and $39 \%$ of patients were female $(\mathrm{p}<0.001$, Fisher's exact test $)$.

\section{Mutation analysis on controls and patients}

Of the 250 controls, one subject was homozygous for the C282Y mutation, seven subjects were homozygous for the H63D mutation, and two subjects were compound heterozygotes (C282Y/H63D) (table 1). The S65C mutation was found in eight subjects, of whom two were compound heterozygotes for either C282Y or H63D, respectively.

Of the 296 unrelated patients, 84 were homozygous for the C282Y mutation, seven were homozygous for the H63D mutation, and 21 patients were compound heterozygotes (C282Y) H63D) (table 1). The S65C mutation was found in 14 unrelated patients, of whom five were compound heterozygotes for either $\mathrm{C} 282 \mathrm{Y}$ or H63D. The frequencies of $\mathrm{C} 282 \mathrm{Y}$, $\mathrm{H} 63 \mathrm{D}$, and $\mathrm{S} 65 \mathrm{C}$ in non-related patients and controls are shown in table 1 . As expected, the number of subjects homozygous for the $\mathrm{C} 282 \mathrm{Y}$ mutation, or compound heterozygous for the $\mathrm{C} 282 \mathrm{Y} / \mathrm{H} 63 \mathrm{D}$ mutations, was significantly increased in patients compared with controls. The number of C282Y heterozygotes, H63D homo- and heterozygotes, and S65C heterozygotes were not significantly different between patients and controls. The TfR2 Y250X mutation could not be detected in any of the 44 patients investigated.

Table 2 demonstrates the mutation frequency of S65C on chromosomes without the $\mathrm{C} 282 \mathrm{Y}$ or H63D mutation, as one mutation excludes the other HFE mutation under study on the same chromosome. The S65C mutation was enriched on chromosomes from patients compared with controls $(\mathrm{p}<0.05$, Fisher's exact test).

Table 3 shows the frequency of patients in whom there was clinical evidence of iron overload in relation to genotype. All patients with a level of iron staining of grade 1 or more on liver biopsy and/or treated with repeated phlebotomies were classified as having iron overload. In 65 patients iron overload could not be evaluated because patient data were missing. The frequency of individuals with clinical iron overload was significantly increased in C282Y homozygotes (89\%) and C282Y/H63D compound heterozygotes (81\%) compared with all other groups, and in H63D heterozygotes (46\%) compared with those having a normal HFE genotype (23\%) (Fisher's exact test). Also, the frequency of patients with clinical iron overload carrying the S65C mutation (S65C simple heterozygotes, S65C/C282Y and S65C/H63D compound heterozygotes pooled together) (7/14) was significantly increased compared with those with the normal HFE genotype (18/79).

\section{Clinical data of patients with the S65C mutation}

Fourteen unrelated patients were heterozygous for the S65C mutation. Clinical data are summarised in table 4. Seven patients underwent liver biopsy due to clinical suspicion of iron overload. Two patients had a slightly increased collagen content in the portal tracts (fibrosis stage 1) but none had signs of extensive liver fibrosis (stage 2 or more). Three patients had HIS grade 2 at Perl's blue staining whereas three patients had grade 1 and one patient grade 0 . In two patients with HIS grade 2,

Table 2 Number of patients and controls with the C282Y and H63D HFE mutations, and allele frequencies of the S65C mutation in chromosomes without the amino acid substitution $\mathrm{C} 282 \mathrm{Y}$ or H63D

\begin{tabular}{llcccc}
\hline C282Y & H63D & $\begin{array}{l}\text { No of patients } \\
(n=296)\end{array}$ & $\begin{array}{l}\text { No of controls } \\
(n=250)\end{array}$ & $\begin{array}{l}\text { S65C alleles* } \\
\text { (patients) }\end{array}$ & $\begin{array}{l}\text { S65C alleles* } \\
\text { (controls) }\end{array}$ \\
\hline$+/+$ & $-/-$ & 84 & 1 & - & - \\
$-/-$ & $+/+$ & 7 & 7 & - & - \\
$+/-$ & $+/-$ & 21 & 2 & - & - \\
$+/-$ & $-/-$ & 30 & 27 & $2 / 30(0.067)$ & $1 / 27(0.037)$ \\
$-/-$ & $+/-$ & 52 & 41 & $3 / 52(0.058)$ & $1 / 41(0.024)$ \\
$-/-$ & $-/-$ & 102 & 172 & $9 / 204(0.044)$ & $6 / 344(0.017)$ \\
& & & & $14 / 286(0.049)^{* *}$ & $8 / 412(0.019)^{* *}$ \\
\hline
\end{tabular}

* On chromosomes with neither the C282Y nor H63D allele.

${ }^{* *} \mathrm{p}=0.0449$ (Fisher's exact test).

Table 3 Number of patients with iron overload* in relation to genotype

\begin{tabular}{lllllc}
\hline C282Y & H63D & S65C & $\begin{array}{l}\text { Total No of } \\
\text { patients }\end{array}$ & $\begin{array}{l}\text { No of patients in } \\
\text { whom data missing }\end{array}$ & $\begin{array}{l}\text { Patients with iron } \\
\text { overload* }\end{array}$ \\
\hline$+/+$ & $-/-$ & $-/-$ & 84 & 19 & $58 / 65(89 \%) \dagger$ \\
$-/-$ & $+/+$ & $-/-$ & 7 & 2 & $3 / 5(60 \%)$ \\
$+/-$ & $+/-$ & $-/-$ & 21 & 5 & $13 / 16(81 \%) \dagger$ \\
$+/-$ & $-/-$ & $+/-$ & 2 & 0 & $1 / 2(50 \%)$ \\
$-/-$ & $+/-$ & $+/-$ & 3 & 0 & $2 / 3(67 \%)$ \\
$+/-$ & $-/-$ & $-/-$ & 28 & 13 & $5 / 15(33 \%)$ \\
$-/-$ & $+/-$ & $-/-$ & 49 & 12 & $17 / 37(46 \%) \dagger$ \\
$-/-$ & $-/-$ & $+/-$ & 9 & 0 & $4 / 9(44 \%)$ \\
$-/-$ & $-/-$ & $-/-$ & 93 & 14 & $18 / 79(23 \%)$ \\
\hline
\end{tabular}

*Patients with iron staining of at least grade 1 on liver biopsy or treated with repeated phlebotomies. $\mathrm{tp}<0.05$ compared with patients without mutations in the HFE gene (Fisher's exact test). 
Table 4 Genotype, biochemical iron parameters, and clinical data in unrelated patients carrying the S65C variant

\begin{tabular}{|c|c|c|c|c|c|c|c|c|c|c|c|c|}
\hline $\begin{array}{l}\text { Pat } \\
\text { No }\end{array}$ & Sex & $\begin{array}{l}\text { Age } \\
(y)\end{array}$ & Genotype & $\begin{array}{l}\mathrm{Hb} \\
(\mathrm{g} / \mathrm{l})\end{array}$ & $\begin{array}{l}\text { Ferritin } \\
(\mu \mathrm{g} / \mathrm{l})\end{array}$ & $\begin{array}{l}\text { TS } \\
(\%)\end{array}$ & $\begin{array}{l}\text { ALT } \\
\text { (U/I) }\end{array}$ & HIS & SIS & $\begin{array}{l}\text { Fibrosis } \\
\text { stage }\end{array}$ & $\begin{array}{l}\text { Phlebotomy } \\
\text { (litre) }\end{array}$ & Diagnosis \\
\hline 1 & M & 24 & C282Y/S65C & 158 & 238 & 77 & 19 & 1 & 0 & 0 & 3.6 & Mild iron overload \\
\hline 2 & $\mathrm{~F}$ & 60 & $\mathrm{C} 282 \mathrm{Y} / \mathrm{S} 65 \mathrm{C}$ & 132 & 324 & 48 & 22 & ND & ND & ND & No & Healthy, surveillance \\
\hline 3 & $\mathrm{~F}$ & 72 & $\mathrm{H} 63 \mathrm{D} / \mathrm{S} 65 \mathrm{C}$ & 145 & 265 & 55 & 45 & ND & ND & ND & No & Healthy, surveillance \\
\hline 4 & M & 49 & $\mathrm{H} 63 \mathrm{D} / \mathrm{S} 65 \mathrm{C}$ & 148 & 536 & 31 & 106 & 2 & 0 & 0 & 1.9 & Mild iron overload, AATdef. \\
\hline 5 & M & 68 & $\mathrm{H} 63 \mathrm{D} / \mathrm{S} 65 \mathrm{C}$ & 154 & 1463 & 53 & 26 & ND & ND & ND & 8.0 & Moderate iron overload, diabetes mellitus \\
\hline 6 & $\mathrm{~F}$ & 55 & $\mathrm{~S} 65 \mathrm{C} / \mathrm{N}$ & 119 & 251 & 41 & 45 & 1 & 0 & 0 & 2.2 & Mild iron overload \\
\hline 7 & M & 64 & $\mathrm{~S} 65 \mathrm{C} / \mathrm{N}$ & 154 & 566 & 44 & 21 & 2 & 1 & 0 & 5.0 & Mild iron overload \\
\hline 8 & $\mathrm{~F}$ & 63 & $\mathrm{~S} 65 \mathrm{C} / \mathrm{N}$ & 141 & 205 & 26 & 25 & 1 & 0 & 0 & No & Mild iron overload \\
\hline 9 & $\mathrm{~F}$ & 72 & $\mathrm{~S} 65 \mathrm{C} / \mathrm{N}$ & 152 & 364 & 41 & 49 & 0 & 0 & 1 & No & Steatosis \\
\hline 10 & M & 58 & $\mathrm{~S} 65 \mathrm{C} / \mathrm{N}$ & 145 & 671 & 28 & 33 & 2 & 1 & 1 & 4.4 & NASH, mild iron overload \\
\hline 11 & $\mathrm{~F}$ & 71 & $\mathrm{~S} 65 \mathrm{C} / \mathrm{N}$ & 135 & 211 & 56 & 22 & ND & ND & ND & No & Ferritin normalised \\
\hline 12 & M & 64 & $\mathrm{~S} 65 \mathrm{C} / \mathrm{N}$ & 161 & 537 & 26 & 42 & ND & ND & ND & No & Diabetes, hypertension, angina pectoris \\
\hline 13 & M & 69 & $\mathrm{~S} 65 \mathrm{C} / \mathrm{N}$ & 137 & 690 & 48 & 5 & ND & ND & ND & No & Emphysema. Alcohol consumption $40-60 \mathrm{~g} / \mathrm{d}$ \\
\hline 14 & $\mathrm{~F}$ & 47 & $\mathrm{~S} 65 \mathrm{C} / \mathrm{N}$ & 135 & 58 & 50 & 24 & ND & ND & ND & No & Healthy \\
\hline
\end{tabular}

$\mathrm{Hb}$, haemoglobin concentration; TS, transferrin saturation; ALT, alanine aminotransferases; HIS, hepatocyte iron score; SIS, sinusoidal iron score; NASH, non-alcoholic steatohepatitis; ND, not determined.

Table 5 Genotypes, biochemical iron parameters, and clinical data for relatives of patients in table 4, found through family screening, and carrying the S65C variant

\begin{tabular}{|c|c|c|c|c|c|c|c|c|c|c|}
\hline Relative No & Sex & $\begin{array}{l}\text { Age } \\
\text { (y) }\end{array}$ & Genotype & $\begin{array}{l}\mathrm{Hb} \\
(\mathrm{g} / \mathrm{l})\end{array}$ & $\begin{array}{l}\text { Ferritin } \\
(\mu \mathrm{g} / \mathrm{l})\end{array}$ & $\begin{array}{l}\text { TS } \\
\text { (\%) }\end{array}$ & $\begin{array}{l}\text { ALT } \\
\text { (U/I) }\end{array}$ & $\begin{array}{l}\text { Liver } \\
\text { biopsy }\end{array}$ & Phlebotomy & Outcome \\
\hline 1 & $\mathrm{~F}$ & 51 & S65C/S65C & 122 & 17 & 8 & 17 & ND & No & Iron deficiency \\
\hline 2 & $\mathrm{~F}$ & 54 & C282Y/S65C & 148 & 251 & 31 & 57 & ND & No & Healthy \\
\hline 3 & $M$ & 26 & $\mathrm{C} 282 \mathrm{Y} / \mathrm{S} 65 \mathrm{C}$ & 152 & 106 & 51 & 29 & ND & No & Surveillance \\
\hline 4 & $\mathrm{~F}$ & 29 & $\mathrm{H} 63 \mathrm{D} / \mathrm{S} 65 \mathrm{C}$ & 140 & 30 & 42 & 32 & ND & No & Healthy \\
\hline 5 & $\mathrm{~F}$ & 26 & $\mathrm{H} 63 \mathrm{D} / \mathrm{S} 65 \mathrm{C}$ & 139 & 27 & 70 & 41 & ND & No & Surveillance \\
\hline 6 & $\mathrm{~F}$ & 33 & $\mathrm{~S} 65 \mathrm{C} / \mathrm{N}$ & 135 & 36 & 15 & 14 & ND & No & Healthy \\
\hline
\end{tabular}

$\mathrm{Hb}$, haemoglobin concentration; TS, transferrin saturation; ALT, alanine aminotransferases; HIS, hepatocyte iron score; SIS, sinusoidal iron score; ND, not determined.

occasional sinusoidal iron deposits (SIS) were also encountered (grade 1). No iron deposits were encountered in biliary ducts or connective tissue. Phlebotomy treatment was initiated in six patients. The amount of blood removed until serum ferritin normalised was 1.9-8.0 litres, as is shown in table 4. None had antibodies against hepatitis B or C. Overconsumption of alcohol was seen in one case.

Table 5 shows the clinical data for six relatives also carrying the $\mathrm{S} 65 \mathrm{C}$ variant, identified through screening of selected family members (patients outlined in table 4). One relative had slightly increased serum ferritin and two had elevated Tf saturation. None underwent liver biopsy.

Table 6 demonstrates the biochemical iron parameters in controls carrying the S65C variant. Three of these eight subjects had slightly elevated serum ferritin, and one had increased $\mathrm{Tf}$ saturation.

In one family, two brothers were found to be compound heterozygotes for C282Y and S65C (patient No 1 in table 4, and relative No 3 in table 5). Screening revealed that their father

Table 6 Genotypes and biochemical iron parameters in controls carrying the S65C variant

\begin{tabular}{lllllll}
\hline $\begin{array}{l}\text { Control } \\
\text { No }\end{array}$ & Sex & $\begin{array}{l}\text { Age } \\
(\mathrm{y})\end{array}$ & Genotype & $\begin{array}{l}\mathrm{Hb} \\
(\mathrm{g} / \mathrm{l})\end{array}$ & $\begin{array}{l}\text { Ferritin } \\
(\mu \mathrm{g} / \mathrm{l})\end{array}$ & $\begin{array}{l}\mathrm{TS} \\
(\%)\end{array}$ \\
\hline 1 & $\mathrm{~F}$ & 56 & $\mathrm{~S} 65 \mathrm{C} / \mathrm{N}$ & 143 & 138 & 37 \\
2 & $\mathrm{M}$ & 67 & $\mathrm{~S} 65 \mathrm{C} / \mathrm{N}$ & 138 & 351 & 32 \\
3 & $\mathrm{~F}$ & 72 & $\mathrm{~S} 65 \mathrm{C} / \mathrm{N}$ & 119 & 198 & 20 \\
4 & $\mathrm{~F}$ & 53 & $\mathrm{~S} 65 \mathrm{C} / \mathrm{N}$ & 115 & 121 & 15 \\
5 & $\mathrm{~F}$ & 26 & $\mathrm{~S} 65 \mathrm{C} / \mathrm{N}$ & 135 & 91 & 35 \\
6 & $\mathrm{M}$ & 29 & $\mathrm{H} 63 \mathrm{D} / \mathrm{S} 65 \mathrm{C}$ & 153 & 432 & 31 \\
7 & $\mathrm{M}$ & 73 & $\mathrm{~S} 65 \mathrm{C} / \mathrm{N}$ & 133 & 437 & 28 \\
8 & $\mathrm{~F}$ & 40 & $\mathrm{C} 282 \mathrm{Y} / \mathrm{S} 65 \mathrm{C}$ & 140 & 58 & 56 \\
\hline
\end{tabular}

$\mathrm{Hb}$, haemoglobin concentration; TS, transferrin saturation. was homozygous for the C282Y mutation and the mother (relative No 1 in table 5) was homozygous for the S65C mutation. The father had clinically manifest $\mathrm{HH}$ which was confirmed by liver biopsy. The mother was found to be iron deficient, possibly due to menstrual blood loss. She had no clinical signs of gastrointestinal bleeding, coeliac disease, or malnutrition. The older of the two sons (26 years of age) (relative No 3 in table 5) had a normal serum ferritin value and a borderline Tf saturation, and liver biopsy was not performed. His younger 24 year old brother carried the same genotype but had a higher serum ferritin and elevated $\mathrm{Tf}$ saturation. Liver biopsy showed liver iron staining of grade 1 and phlebotomy treatment was started. Serum biochemical analyses of this family are shown in table 7 .

\section{Biochemical analyses in control subjects}

In fig 1 , serum ferritin and Tf saturation in control subjects with different genotypes are demonstrated. Only two control subjects had significantly increased serum ferritin values compared with subjects with other genotypes. One of these was homozygous for the $\mathrm{C} 282 \mathrm{Y}$ mutation and the other was compound heterozygous for the H63D/S65C mutation. Subjects heterozygous for the S65C mutation alone had significantly increased serum ferritin levels compared with those heterozygous for either $\mathrm{C} 282 \mathrm{Y}$ or $\mathrm{H} 63 \mathrm{D}$, homozygous for H63D, compound heterozygous for C282Y/H63D, or without a HFE mutation (fig 1A). There was no correlation between ferritin and age in controls $\left(r^{2}=0.04\right)$. Tf saturation was significantly increased in the subject homozygous for C282Y and the subject with compound heterozygosity for C282Y/ S65C compared with the other groups (fig 1B).

\section{Biochemical analyses in patients with suspected iron overload}

Figure 2 demonstrates serum ferritin and Tf saturation in 218 and 206 patients, respectively, in whom the exact serum 
Table 7 HFE mutations, serum ferritin, and transferrin saturation in members of a family carrying the $\mathrm{C} 282 \mathrm{Y}$ and S65C mutations

\begin{tabular}{lllllll}
\hline Family member & HFE mutation & $\begin{array}{l}\mathrm{Hb} \\
(\mathbf{g} / \mathbf{l})\end{array}$ & $\begin{array}{l}\text { TS } \\
(\%)\end{array}$ & $\begin{array}{l}\text { Serum ferritin } \\
(\mu \mathrm{g} / \mathrm{I})\end{array}$ & $\begin{array}{l}\text { ALT } \\
(\mathrm{U} / \mathrm{I})\end{array}$ & $\begin{array}{l}\text { Iron staining at } \\
\text { liver biopsy }\end{array}$ \\
\hline Father & $\mathrm{C} 282 \mathrm{Y} / \mathrm{C} 282 \mathrm{Y}$ & 154 & $93 \%$ & 1311 & 34 & Grade 4 \\
Mother & $\mathrm{S} 65 \mathrm{C} / \mathrm{S} 65 \mathrm{C}$ & 122 & $17 \%$ & 8 & 16 & $\mathrm{ND}$ \\
Son (26 years old) & $\mathrm{C} 282 \mathrm{Y} / \mathrm{S} 65 \mathrm{C}$ & 152 & $51 \%$ & 106 & 29 & $\mathrm{ND}$ \\
Son (24 years old) & $\mathrm{C} 282 \mathrm{Y} / \mathrm{S} 65 \mathrm{C}$ & 158 & $77 \%$ & 238 & 19 & Grade 1 \\
\hline
\end{tabular}

$\mathrm{Hb}$, haemoglobin concentration; $\mathrm{TS}$, transferrin saturation; $\mathrm{ALT}$, alanine aminotransferases; $N D$, not determined.

ferritin values or $\mathrm{Tf}$ saturation at diagnosis were available from the patient files. As expected, serum ferritin was significantly increased in $\mathrm{C} 282 \mathrm{Y}$ homozygotes compared with the other HFE genotypes (fig 2A). H63D homozygotes had significantly increased serum ferritin levels compared with compound heterozygotes (C282Y/H63D) or those without a HFE mutation. Patients carrying the S65C mutation had similar serum ferritin values as those without a HFE mutation. Tf saturation was significantly increased in patients homozygous for C282Y compared with all groups, except H63D homozygotes or C282Y/S65C compound heterozygotes (fig 2B). A significant increase in Tf saturation was also found in S65C/C282Y or S65C/H63D compound heterozygotes compared with those without HFE mutations. No significant differences were seen in serum ferritin or Tf saturation between S65C simple heterozygotes and S65C/C282Y or $\mathrm{S} 65 \mathrm{C} / \mathrm{H} 63 \mathrm{D}$ compound heterozygotes.

\section{DISCUSSION}

The present study was conducted: (A) to determine the HFE S65C frequency in an urban population of Northern European origin, and (B) to evaluate whether or not the presence of the
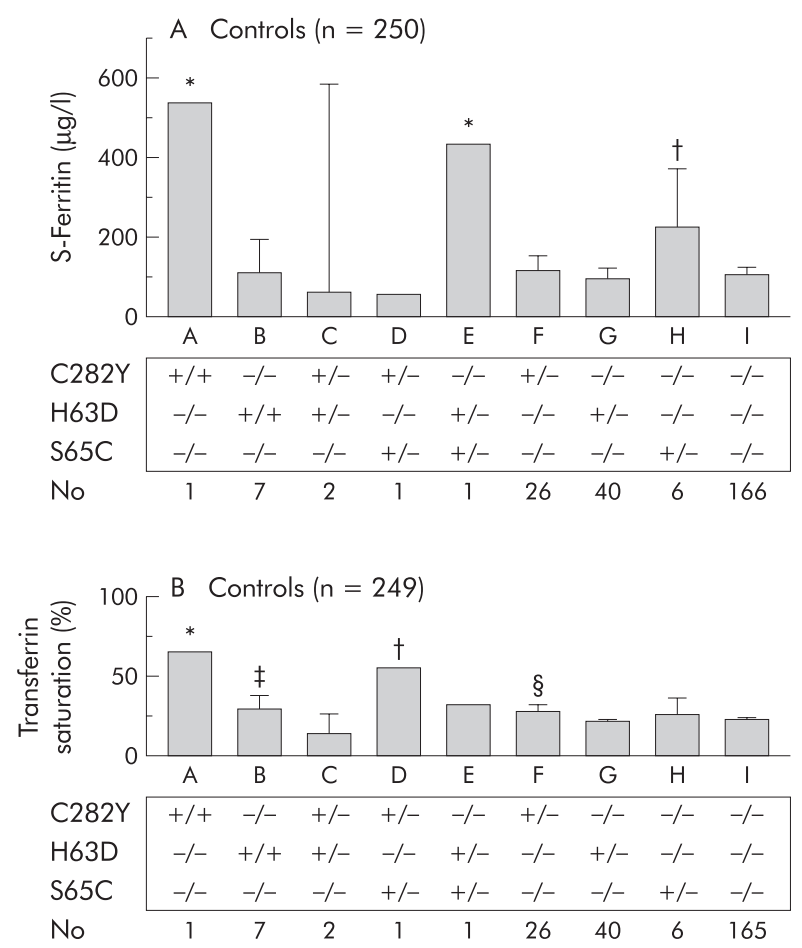

Figure 1 Biochemical iron parameters in control subjects with different HFE genotypes. (A) Serum ferritin levels $(n=250) .{ }^{*} p<0.05$ versus $B, C, D, F, G, H, I ; \dagger p<0.05$ versus $B, C, F, G$, I. (B) Serum transferrin saturation $(n=249)$. ${ }^{*} p<0.05$ versus $B, C, E, F, G, H, I$; $\dagger p<0.05$ versus $B, C, E, F, G, H, I ; \neq p<0.05$ versus $C, G ; \xi p<0.05$ versus $C, G$, I.
HFE S65C mutation results in significant hepatic iron overload. For these purposes two groups of individuals were investigated; 250 healthy controls and 296 patients admitted to hospital for clinical suspicion of iron overload. The latter group was heterogenous as inclusion criteria were wide (increased serum ferritin and/or Tf saturation) excluding only patients with acute liver failure or malignant diseases that
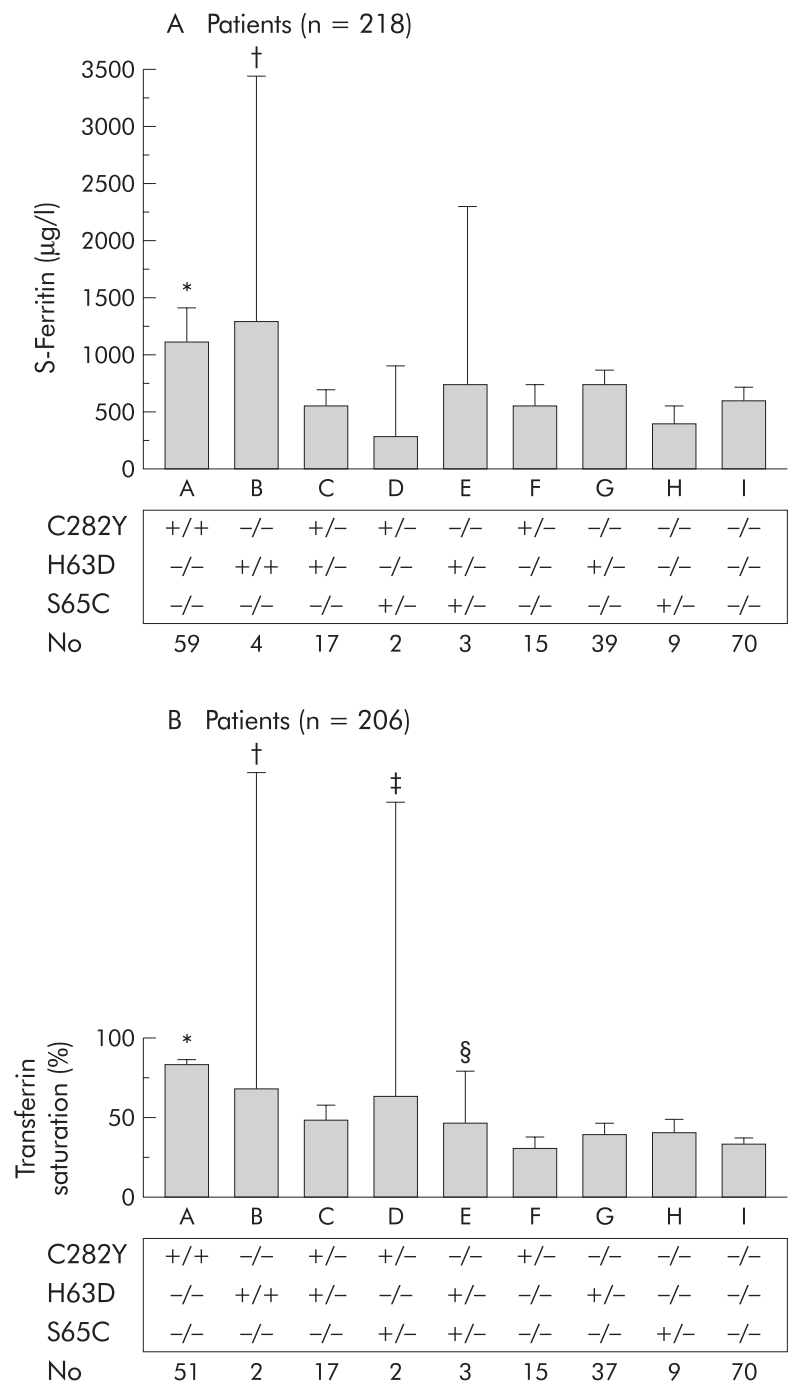

Figure 2 Biochemical iron parameters at the time of diagnosis in patients with suspected iron overload. (A) Serum ferritin levels in 218 of 296 patients in whom serum ferritin values were available from patient files. ${ }^{*} p<0.05$ versus $F, G, H, I ; \dagger p<0.05$ versus $C$, I. (B) Serum transferrin saturation in 206 of 296 patients in whom transferrin saturation values were available from patient files. ${ }^{*} p<0.05$ versus $C, E, F, G, H, I ; \dagger p<0.05$ versus $F, G, H, I$; $\ddagger p<0.05$ versus $F, I ; \S p<0.05$ versus $F$, I. 
Table 8 Allelic frequencies of the HFE C282Y, H63D, and S65C mutations in control subjects or in the general population in different studies evaluating the frequency of the HFE S65C variant

\begin{tabular}{|c|c|c|c|c|}
\hline Author & Country & $\mathrm{C} 282 \mathrm{Y}$ & H63D & S65C \\
\hline Mura et $a l^{12}$ & Brittany, France & 0.077 & 0.14 & 0.0195 \\
\hline Remacha et a ${ }^{25}$ & Barcelona, Spain & $0.20 \ddagger$ & $0.15 \ddagger$ & $0.0036 \dagger \ddagger$ \\
\hline \multirow{6}{*}{$\begin{array}{l}\text { Barton et } a^{21} \\
\text { Beutler et } a l^{11}\end{array}$} & Alabama, USA & 0.099 & 0.145 & 0.006 \\
\hline & California, USA & & & \\
\hline & Caucasians & 0.063 & 0.152 & 0.016 \\
\hline & Hispanic & 0.027 & 0.124 & 0.006 \\
\hline & Asian & 0.002 & 0.033 & 0 \\
\hline & Black & 0.011 & 0.051 & 0.007 \\
\hline \multirow[t]{2}{*}{ Arya et $a{ }^{23}$} & Ontario, Canada & ND & $\mathrm{TS}>45 \%: 0.248 *$ & $\mathrm{TS}>45 \%: 0.017^{*}$ \\
\hline & & & $\mathrm{TS}<45 \%: 0.147^{*}$ & $\mathrm{TS}<45 \%: 0.022$ * \\
\hline \multirow[t]{5}{*}{ Beckman et al ${ }^{15}$} & Northern Sweden & & & \\
\hline & Finns (northern part) & 0.046 & 0.098 & 0.023 \\
\hline & Saamis & 0.020 & 0.079 & 0.030 \\
\hline & Swedes (northern part) & 0.070 & 0.117 & 0.012 \\
\hline & Swedes (southern part) & 0.054 & 0.128 & 0.014 \\
\hline Present study & Stockholm, Sweden & 0.062 & 0.114 & 0.016 \\
\hline
\end{tabular}

would explain the increased serum ferritin values, or patients found through screening of relatives. Fourteen patients and eight controls carried the S65C variant. The former group were investigated more thoroughly with collection of clinical data (as shown in table 4).

In our control subjects, allele frequencies of the C282Y, $\mathrm{H} 63 \mathrm{D}$, and S65C mutations were $6.2 \%, 11.4 \%$, and $1.6 \%$, respectively. One individual was homozygous for the $\mathrm{C} 282 \mathrm{Y}$ mutation whereas two subjects were compound heterozygous for C282Y/H63D. Six individuals were S65C simple heterozygotes and two were compound heterozygotes having S65C in combination with either $\mathrm{C} 282 \mathrm{Y}$ or $\mathrm{H} 63 \mathrm{D}$. Our results confirm the $H F E$ mutation frequencies from other studies in subjects with a Northern European ancestry (table 8). The highest frequency of S65C has been found in the Saami population of Northern Scandinavia (3.0\%), ${ }^{15}$ a slightly lower frequency was seen in Caucasians of Northern European origin (1.2$2.3 \%)^{1112} 1523$ and the lowest frequency was in individuals of Hispanic, Asian, or African origin (0.0-0.7\%) (table 8). ${ }^{11} 2125$

We found that $\mathrm{S} 65 \mathrm{C}$ allele frequency was enriched in nonC282Y non-H63D chromosomes from patients $(4.9 \%)$ compared with control subjects $(1.9 \%)(\mathrm{p}<0.05)$. These results are in line with those reported in a French population by Mura and colleagues, ${ }^{12}$ and indicate that the S65C mutation may be of importance for increased iron accumulation.

In controls, we found a significant increase in serum ferritin in individuals heterozygous for the S65C mutation compared with wild-type HFE, or H63D or C282Y heterozygotes (fig lA). However, Tf saturation was not significantly higher in those controls carrying the S65C mutation compared with those with wild-type HFE, a finding also previously observed in voluntary blood donors. ${ }^{23}$ In our patients, serum ferritin was increased in all groups, but as expected, significantly higher only in C282Y homozygotes and C282Y/ H63D compound heterozygotes. Patients carrying S65C had similar ferritin values as those heterozygous for the other HFE mutations. On the other hand, patients carrying compound heterozygosity for S65C and C282Y or H63D $(n=5)$ had significantly increased Tf saturation compared with those with no HFE mutations. These data indicate that S65C heterozygosity or compound heterozygosity (with C282Y or H63D) may play a role in the development of mild iron overload but possibly not fully developed haemochromatosis.

These observations prompted us to study the 14 patients carrying the S65C mutation in more detail. Of these, seven underwent liver biopsy, of which six displayed a mild or moderate hepatic iron overload (grade 1 or 2 ) while one had no stainable liver iron. Five of six patients with stainable liver iron were treated with phlebotomy (table 4 ). In one additional patient with a serum ferritin level of $1463 \mu \mathrm{g} / \mathrm{l}$, hepatic iron overload was strongly suspected but the patient refused liver biopsy. Phlebotomy treatment was initiated and a total of 8.0 litres of blood were removed before serum ferritin normalised. Thus this patient was considered to have hepatic iron overload (table 4). In patients with the S65C mutation, total blood volumes removed at phlebotomy were smaller than usually required in patients carrying $\mathrm{C} 282 \mathrm{Y}$ homozygosity. Interestingly, none of the biopsies showed histopathological signs of extensive liver fibrosis or cirrhosis, in spite of the fact that one patient had signs of mild non-alcoholic steatohepatitis and one was heterozygous for $\alpha_{1}$ antitrypsin deficiency. None of the patients carrying the S65C mutation had antibodies against hepatitis B or C, and marked alcohol consumption was seen in only one case (not liver biopsied), facts which may explain the mild liver pathology. Thus in half (7/14) of our patients with increased iron indices who carried the S65C mutation, mild to moderate iron overload was encountered, and in those whom hepatic iron overload was strongly suspected only $1 / 8$ was iron negative in the liver.

We also asked if iron overload could be encountered in the relatives of our patients with the S65C mutation. Data on six relatives of our patients with the HFE S65C variant were collected, as shown in table 5 . All of these were healthy and found through voluntary screening. Only one 54 year old female had increased serum ferritin $(251 \mathrm{\mu g} / \mathrm{l})$ and two 26 year old subjects had increased Tf saturation ( $51 \%$ and $70 \%)$. None had undergone liver biopsy or had been treated with phlebotomy. Among the eight control subjects carrying the S65C mutation, four had elevated iron indices (three increased serum ferritin and one increased Tf saturation) (table 6). Thus half of the S65C positive healthy controls and relatives displayed mildly elevated iron indices.

When we investigated the relatives of one patient carrying the C282Y/S65C genotype (patient No 1 in table 4), his older brother was found to carry the same genotype while his father was homozygous for the $\mathrm{C} 282 \mathrm{Y}$ mutation and his mother was homozygous for the S65C mutation. Surprisingly, she had depleted iron stores with signs of iron deficiency, possibly due to menstrual blood loss. The two brothers carrying the same genotype had different phenotypic expression of the disease, 
the younger of which had the highest serum ferritin and Tf saturation (table 7).

When evaluating the possibility that S65C may lead to significant hepatic iron overload, we attempted to classify all patients in the study as being iron overloaded or not on the basis of positive iron staining in the liver biopsy (grade 1 or more) or whether or not phlebotomies had been carried out. For 231 of the 296 patients, data on liver biopsy, iron content, and/or phlebotomy treatment (if performed or not) were collected. Only C282Y homozygotes and C282Y/H63D compound heterozygotes had significantly higher frequencies of iron overloaded subjects compared with the other genotypes. In this respect, S65C simple heterozygotes did not differ significantly from those without HFE mutations. However, if all patients carrying the S65C mutation were pooled, 7/14 (50\%) were considered to have at least mild hepatic iron overload which was significantly more compared with patients without any HFE mutation $(23 \%)$. Thus these data strengthen the hypothesis that S65C carriers have a risk of developing iron overload but not to the same extent as C282Y homozygotes or C282Y/H63D heterozygotes.

In our study, we were unable to match controls and patients regarding age and sex, as our patients with increased iron indices were older and showed a predominance of males compared with controls who were selected from hospital staff and students. However, our sample of controls allows for comparison of allele frequencies with those in the general population, and our results in controls showed good agreement regarding allele frequencies and prevalence of HFE mutations among populations of Northern European ancestry (table 8). The only comparisons between patients and controls that were carried out were for gene frequencies. Also, the frequency of C282Y homozygotes among our patients was lower than that in other studies comparing $\mathrm{HH}$ patients with controls. ${ }^{12}$ A possible explanation is the heterogeneity of our patient group regarding the causes of the increased iron parameters, including not only patients with $\mathrm{HH}$ but also subjects with hyperferritinaemia or increased Tf saturation due to other aetiologies (with the exception of acute liver failure, thyreotoxicosis, and hepatic or haematological malignancy). This heterogeneity however would not affect the conclusions of our study.

The mild iron overload seen in patients carrying the S65C mutation may be due to a similar functional effect on the HFE protein as induced by the H63D mutation since the S65C substitution is located only two amino acid residues C terminally to the H63D substitution. Possibly the S65C mutation may affect the binding of HFE to the TfR, and subsequently the affinity of TfR to Tf, in a similar way to the H63D substitution. ${ }^{10}$ However, there are no cell transfection studies to prove this to date.

Mutations other than C282Y, H63D, and S65C in the HFE gene may also contribute to increased iron accumulation. For example, we found mild iron overload in 18 patients without any detectable mutations in HFE (table 3 ). Also, the different phenotypic expression of two brothers with an identical genotype C282Y/S65C indicates the influence of additional mutations. Therefore, these two brothers (table 7) and 42 patients without HFE mutations were analysed regarding a previously described HH associated mutation (Y250X) in the TfR2 gene which however could not be detected in any of the cases.

In conclusion, we found that the HFE S65C mutation was enriched in patients with high serum ferritin or increased Tf saturation compared with healthy controls. Half of our patients carrying the S65C mutation had evidence of mild or moderate hepatic iron overload (grade 1 or 2) but no signs of extensive fibrosis. Furthermore, $50 \%$ of healthy controls and relatives carrying the $\mathrm{S} 65 \mathrm{C}$ mutation had increased serum ferritin levels and $\mathrm{Tf}$ saturation. The increase in serum ferritin in S65C positive controls was significant compared with those without HFE mutations. When all 14 patients with a S65C
HFE variant were pooled, the number of iron overloaded individuals was significantly higher compared with those without HFE mutations although serum ferritin values were similar. Taken together, these data indicate that S65C may be of importance for the development of mild to moderate hepatic overload but possibly with a negligible risk for iron associated liver cirrhosis.

\section{ACKNOWLEDGEMENTS}

This study was supported by grants from the Swedish Medical Research Council (project No 11549), the Swedish Society of Medicine (Bengt Ihres Fund), the Nanna Svartz Foundation, and the Ragnhild and Einar Lundströms Memory Foundation. We are indebted to Mrs Marianne Vallin for expert assistance with the mutation analyses.

\section{Authors' affiliations}

P Holmströmt, G Eggertsen, $\mathbf{M}$ Gåfvels, Division of Clinical Chemistry, Department of Medical Laboratory Science and Technology, Karolinska Institutet, Huddinge University Hospital, Stockholm, Sweden

J Marmurt, Division of Gastroenterology and Hepatology, Department of Medicine, Karolinska Institutet, Huddinge University Hospital,

Stockholm, Sweden

P Stål, Unit of Gastroenterology and Hepatology, Department of Internal Medicine, Karolinska Institutet, Danderyds Hospital, Stockholm, Sweden

†P Holmström and J Marmur contributed equally to this work.

\section{REFERENCES}

1 Deugnier YM, Loreal O, Turlin B, et al. Liver pathology in genetic hemochromatosis: a review of 135 homozygous cases and thei bioclinical correlations. Gastroenterology 1992;102:2050-9.

2 Niederau C, Fischer R, Purschel A, et al. Long-term survival in patients with hereditary hemochromatosis. Gastroenterology 1996;110:110719.

3 Adams PC, Chakrabarti S. Genotypic/phenotypic correlations in genetic hemochromatosis: evolution of diagnostic criteria. Gastroenterology 1998;114:319-23.

4 Feder JN, Gnirke A, Thomas W, et al. A novel MHC class I-like gene is mutated in patients with hereditary haemochromatosis. Nat Genet 1996; 13:399-408

5 Feder JN, Tsuchihashi Z, Irrinki A, et al. The hemochromatosis founder mutation in HLA-H disrupts beta2-microglobulin interaction and cell surface expression. J Biol Chem 1997;272:14025-8.

6 Rothenberg BE, Voland JR. Beta2 knockout mice develop parenchymal iron overload: A putative role for class I genes of the major histocompatibility complex in iron metabolism. Proc Natl Acad Sci U S A 1996:93:1529-34.

7 Santos M, Schilham MW, Rademakers LH, et al. Defective iron homeostasis in beta 2-microglobulin knockout mice recapitulates hereditary hemochromatosis in man. J Exp Med 1996;184:1975-85.

8 Feder JN, Penny DM, Irrinki A, et al. The hemochromatosis gene product complexes with the transferrin receptor and lowers its affinity for ligand binding. Proc Natl Acad Sci U S A 1998;95:1472-7.

9 Salter-Cid L, Brunmark A, Li Y, et al. Transferrin receptor is negatively modulated by the hemochromatosis protein HFE: implications for cellular iron homeostasis. Proc Natl Acad Sci U S A 1999;96:5434-9.

10 Waheed A, Parkkila S, Zhou XY, et al. Hereditary hemochromatosis: effects of $\mathrm{C} 282 \mathrm{Y}$ and $\mathrm{H} 63 \mathrm{D}$ mutations on association with beta2-microglobulin, intracellular processing, and surface expression of the HFE protein in COS-7 cells. Proc Natl Acad Sci U S A 1997:94:12384-9.

11 Beutler E, Felitti V, Gelbart T, et al. The effect of HFE genotypes on measurements of iron overload in attending a health appraisal clinic. Ann Int Med 2000; 133:329-37

12 Mura C, Raguenes O, Ferec C. HFE mutations analysis in 711 hemochromatosis probands: evidence for $\mathrm{S} 65 \mathrm{C}$ implication in mild form of hemochromatosis. Blood 1999;93:2502-5.

13 Olynyk JK, Cullen DJ, Aquilia S, et al. A population-based study of the clinical expression of the hemochromatosis gene. N Engl J Med 1999;341:718-24.

14 Cardoso EM, Stal P, Hagen K, et al. HFE mutations in patients with hereditary haemochromatosis in Sweden. J Int Med 1998;243:203-8.

15 Beckman LE, Sjoberg K, Eriksson S, et al. Haemochromatosis gene mutations in Finns, Swedes and Swedish Saamis. Hum Hered 2001;52:110-12.

16 Jazwinska EC, Cullen LM, Busfield F, et al. Haemochromatosis and HLA-H. Nat Genet 1996;14:249-51

17 Merryweather-Clarke AT, Pointon JJ, Shearman JD, et al. Global prevalence of putative haemochromatosis mutations. J Med Gene 1997;34:275-8

18 Piperno A, Sampietro M, Pietrangelo A, et al. Heterogeneity of hemochromatosis in Italy. Gastroenterology1998;1 14:996-1002. 
19 Carella M, D'Ambrosio L, Totaro A, et al. Mutation analysis of the HLA-H gene in Italian hemochromatosis patients. Am J Hum Genet 1997;60:828-32.

20 Papanikolaou G, Politou M, Terpos E, et al. Hereditary hemochromatosis: HFE mutation analysis in Greeks reveals genetic heterogeneity. Blood Cell Mol Dis 2000;26:163-8.

21 Barton JC, Sawada-Hirai R, Rothenberg BE, et al. Two novel missense mutations of the HFE gene (1105T and G93R) and identification of the S65C mutation in Alabama hemochromatosis probands. Blood Cell Mol Dis 1999;25:147-55.
22 Camaschella C, Roetto A, Cali A, et al. The gene TFR2 is mutated in a new type of haemochromatosis mapping to $7 \mathrm{q} 22$. Nat Genet 2000;25: 14-15.

23 Arya N, Chakrabrati S, Hegele RA, et al. HFE S65C variant is not associated with increased transferrin saturation in voluntary blood donors. Blood Cell Mol Dis 1999;25:354-7.

24 Rappaport A. Hepatic blood flow: morphological aspects and physiological regulation. Int Rev Physiol 1980;21:1-63.

25 Remacha AF, Barcelo M, Sarda MP, et al. The S65C mutation in Spain. mplications for iron overload screening. Haematologica 2000:85:1324-5.

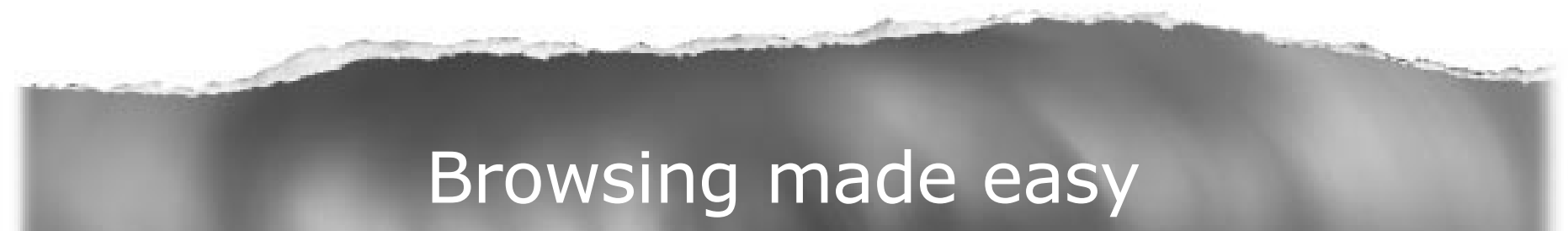

\section{Collections}

With a single click Collections allows you to find all articles that have been published in your chosen subject. Select from over 200 clinical and non-clinical topic collections and/or cross search other specialist journals, the BMJ and Cochrane Reviews

\section{www.gutjnl.com}

